\title{
The Transcending Age: A Study of Psycho-social Wellbeing of Elderly Women in India
}

\author{
Sabiha Hussain ${ }^{1, *}$ \\ ${ }^{1}$ Sarojini Naidu Centre for Women's Studies, Jamia Millia Islamia (Central University), New \\ Delhi-110025, India \\ *Corresponding author: Sarojini Naidu Centre for Women's Studies, Jamia Millia Islamia (Central \\ University), New Delhi-110025, India. Tel: 91-989-917-4874. E-mail: Shussain1@jmi.ac.in \\ Received: August 18, 2020 Accepted: December 1, 2020 Published: January 14, 2021 \\ doi:10.5296/jsr.v12i1.18210 URL: https://doi.org/10.5296/jsr.v12i1.18210
}

\begin{abstract}
India is witnessing rapid growth of elderly population. The population aged 60 years or older is projected to climb from $9 \%$ in 2015 to $19 \%$ in 2050 and to $32 \%$ in 2100 (UN, 2017). Aging population requires attention on their physical, social and emotional well-being. Wellbeing encompasses multiple interactive components which are beyond the conventional issues of health and diseases. There is multitude of social relationships and dynamics of social roles that women in this age negotiate in their lives. Family dynamics, compatibility with partner, household headship, decision making and level of autonomy, incidences of domestic violence, security concerns, care-giving, perceptions of self, societal status do influence quality of life and wellbeing.

Using primary survey data of 165 women aged 60 to 65 years residing in urban areas in Delhi-National Capital Region (NCR) interviewed during first quarter of 2018, the paper attempts to understand what does well-being mean to them, how do they ensure it, what are the psycho-social barriers and how do they overcome them. Purposive sampling and snowballing techniques has been employed to identify these women.

Increase in health related problems especially mobility issues, lifestyle diseases along with depression were predominant in this age. For women in post 60 years of age, respect and appreciation from family and society is vital to ensure their happiness, while family bonding and overall contentment stands out for ensuring wellbeing. Religious pursuits and social interaction are the fundamental coping mechanisms from stress. Inadequate and incomplete education and early marriage rooted in patriarchy and financial dependence are the principal sources of regret in lives of these women. Widowed women were identified as the most vulnerable. Women in the lowest income group and literacy level were further marginalized and needed help from state. Evident gaps were reported in the existing welfare government schemes for this age.
\end{abstract}

Keywords: wellbeing, family, health, aging, social interaction 


\section{Introduction}

"Aging itself is not inevitably associated with a decline in mood and quality of life. It is rather the case that psychosocial factors such as depression or anxiety impair subjective well-being." Prof. Karl-Heinz Ladwig

Aging of population is a global phenomenon and India is no different. According to the Census of India 2011, India is home to the 98.3 million 60 plus age group(Note 1). The wellbeing of older persons is mandated in the Constitution of India under Article 41(Note 2). It is important to visualise the difference in what constitutes wellbeing for women in this group who have transcended into aging relative to the younger age cohorts in the middle age (45 to 59 years). Older people are often assumed to be frail or dependent, and a burden to society. Public health, and society as a whole, needs to address these and other ageist attitudes, which can lead to discrimination and can also affect the ways policies are developed.

It is to be noted that there are conditions which promote successful ageing which must be considered. Psychology has much to contribute to public awareness of healthy ageing and the diversity of human experience in ageing patterns, family support structures and meaningful community involvements in later life. Aging population need to given focused attention on their physical, social and emotional well-being. Nevertheless, the ageing women experience a range of changes, physical as well as psychological and this period is known as the period of serious crises.

\subsection{Aging and Psycho-social Well Being: Theoretical Framework}

A few studies (Steverink et al., 2001) indicates that people with better subjective health, higher income, less feeling of loneliness, higher educational level, and greater optimism would tend to experience a healthier aging process in terms of continuous development than of physical deterioration or social losses. This healthy aging in older people further leads to a higher emotional well-being and a better aging experience (Prieto-Flores et al., 2008). Similarly, the psycho-social variables such self-acceptance; positive relationships with other people; autonomy; domain of the environment; purpose in life; and personal growth plays important role in healthy aging. Ryffs has rightly pointed out that psychological well-being is the effort to perfect one's own potential. Thus it would have to do with life acquiring meaning for oneself, with certain efforts to overcome and achieve valuable goals. The central task of the people in your life is to recognize and make the most of all your talents. He stressed the responsibility of the individual to find the meaning of one's existence, even in the face of harsh or adverse realities. Hence, it must therefore be understood that psychological well-being as personal construction rests on the psychological development of each individual who has the ability to interact amicably with their environment (Ortiz Arriagada \& Salas, 2009).

Therefore, it is imperative to understand the fact that aging is a process inherent to the passage of time that involves certain transformations and vital transactions in the individual. The course of this process and its consequences, is controlled by personal variables on the one hand and on the other by those derived from a broader psycho-socio-cultural context (Borrellet al., 2011). In 
other words, literature on well being in the old age emphasize on both health and quality of life. Graham and Shier (2010) consider well being as to how people make sense of their lives. More precisely, it refers to satisfaction, lack of depression and anxiety, and positive moods and emotions. The state of well-being is a multifaceted phenomenon in the older population which generally involves happiness, self-contentment, satisfying social relationships, and autonomy (Kunzmann and Smith, 2000). Thus the sense of well-being refers to an individual's feelings or perception, in this case, based on how older people perceive the concept of well-being (Francis Spirduso and Macrae, 2005). Further, well being is also subject to other persons' feelings about oneself whether that is positive or negative. According to McNulty et, al (2012) well-being is determined jointly by the interplay between individual characteristics and qualities of people's social environments. Thus, the meaning of well being can be linked to the larger concept of quality of life which generally involves a subjective experience and external measurable conditions.

\subsection{Elderly Women and Well being}

Generally old age is supposed to be the golden age for elderly as at this age all responsibilities are done. During the sunset years, when all their responsibilities as parents are fulfilled and when they are looking forward for adequate care and support from their children, they are deprived of it due to economic, social and psychological factors. However, women are more vulnerable as compared to men in their old age for various socio-cultural and economic reasons in general and in Indian context in particular. Asharaf (2005) discusses about the factors creating hardship for women namely; the feminine nature of ageing, society's discriminatory treatment towards women's education and employment and social discrimination and ill treatment because of the traditional roles attached to women in society. Such traditional attitudes and discriminations have made lives of women vulnerable especially in their old age. Penhale and Kingston (1995) in their study noted that to be old in the UK, is to be marginalized which is single jeopardy; to be old and abused is double jeopardy; and to be old, abused and female is triple jeopardy. Prakash (2001), points out that problems of elderly women are not due to age per se, but due to psychosocial environment, diminishing supports and changes in life situation. Kalyan (1998) has also pointed out that even though both elderly men and women goes through the same biological process of ageing with progressive functional decline, women from womb to tomb leads a life vulnerable to numerous hazards of direct and indirect in nature and one of them is gender discrimination and widowhood. This further aggravates their misery due to acute economic dependency and social isolation. However, little research has been done on the psycho-social well being of persons in old age within the discipline of gerontology, sociology, Social work and Gender Studies. Hence, this paper is an attempt to explore the psycho-social well being of elderly people from multidisciplinary perspectives. In other words, this paper does not deal with scientific facts of Psycho-social well being but rather more concerned about the material representation of abstract experiences and concept of well being of the elderly women. 


\section{Objectives}

The paper attempts to comprehend about what constitutes the psycho-social wellbeing of the aged women of age 60 years and above? How does the diversity in social, economic and cultural background impacts the wellbeing of this age group living in metropolitan city? In what ways does health and physical fitness affects the aging women's wellbeing? Does transcending age influence psychological health amongst women? What are the barriers to the psycho-social wellbeing of women and effects of coping mechanisms adopted by them to ensure this? Do aging women find space in policy and planning of the state?

\section{Database and Methodology}

The study was conducted in the urban areas in Delhi/NCR in the later quarter of 2018. Purposive sampling method along with use of snowballing techniques was used to identify and interview the women. Keeping in mind the parity in distribution of the sample and to avoid statistical bias; that women belonging to different socio-economic strata and diversely located across the geographical regions within the study area. The total sample consists of 200 respondents belonging to low, middle and high-income group along with diverse social and religious groups.

The data was collected using a specially designed interview schedule and observation technique through a house-to-house survey for those residing in the family. Prior to final data collection, the interview schedule was tested on a small subsample and subsequently finalized, upon successful testing and minor modifications. A semi-structured interview schedule with both closed and open ended questions pertaining to general information of the respondents, questions pertaining to general feelings of elderly women to happiness, loneliness, depression, security, insecurity, dynamics of family relationship, self perception and societal perception towards the women different factors leading to stress and coping mechanism was sought. The questionnaire was both description and analytical. A verbal consent was received from the respondents before the interview, informing them the purpose and utility of the research.

\subsection{General Information of the Respondents}

Women in 60-65 years of age group in our sample belonged to diverse socio-religious and economic backgrounds. 63.6 percent of the respondents were Hindus, 30.3 percent were Muslims, 4.8 percent Sikhs and 1.2 percent Christians. In terms of social groups the 67.9 percent of the respondents belonged to general castes, 18.2 percent were from other backward classes (OBCs) and 13.9 percent were scheduled castes (SCs). About 58.8 percent were currently married, 33.9 percent of the women in this age group are widows, 3.0 percent are separated or divorced and 4.2 percent were unmarried. 30.0 percent of the women in this age group were married off before the legal age of 18 years. Nine women reported to have some kind of disability. 41.6 percent of the women in our sample were uneducated while 6.1 percent and 3.6 percent were educated up to primary and elementary level of schooling. The remaining 15.2 percent were educated at secondary level of schooling, 18.2 percent were graduates and $16.4 \%$ were postgraduates and above. The reasons cited by the women for 
never being enrolled in school or dropping out were primarily due to societal compulsions and traditional patriarchal discriminations. Gender bias (25.0 percent) and early marriage (17.0 percent) came out as the predominant reasons followed by 10.2 percent due to poverty, death of parents and early entry in job market owing to financial crisis as the reason for dropping out. The proportion of illiterates among the Muslim women was higher at 63.0 percent compared with 33.3 percent among the Hindus.

Anisha Khan, aged 62 years regrets 'I wished to go to school as a young girl and used to watch children from my window, who used to go to school in uniform and school bags. I wanted to dress up like them and go to school. But girls from affluent Muslim families were not allowed to go to school and study. I regret not being educated.'

With regards to living arrangements, 5.5 percent women were living alone, 35.2 percent were in joint families and 55.8 percent in nuclear family setup. Almost 60.0 percent of the women were living in households with more than five members, only 20.0 percent lived in two member households. Interestingly, 42.0 percent households were female headed, 9.0 percent were male headed and the remaining 49.0 percent were jointly headed. It is also interesting to mention here that as men aged they become passive and role reversal at times happen in the family dynamics. This can be seen in our study as 24 percent married women in our sample perceive themselves as head of their households. This also happens as the woman transforms from a wife to a mother in-law in some circumstances leading to a role change. As far as the economic status of the respondent is concerned, 48.5 percent almost of the respondents had a monthly household income of less than Rs 20000 , followed by 23.6 percent, 15.8 percent had a monthly income of 20001-50000 and 12.1 percent had a monthly income of 50000 and above. The economic status of the women can be also assessed from the ownership figures of durable assets by their households. Land is possessed by 10.9 percent households, car by 21.9 percent and house by 38.2 percent of the households of the women 60 years and above. As far as employment status is concerned, only 20.6 percent women were employed in paid work (salaries or wages) followed by 10.0 percent retired pensioners, 4.2 percent teachers and 3.0 percent women earned meager sustenance from home-based, piece-rate work such as tailoring.

\section{Results and Discussion}

With age women suffer major health related issues associated with hormonal changes, metabolism changes and degrading bone and muscle health. Thus it becomes necessary to have a balanced diet rich in supplements and do some physical activities. This section highlights various dimensions of health and well being of the women under study that includes: physical and mental health, diet and physical activities, sleep pattern, me time or leisure, along with changing family dynamics in terms of relationship and decision making.

\subsection{Diseases and Treatment: Respondents View}

There is, however, little evidence to suggest that older people today are experiencing their later years in better health than their parents. A study done in US reveals that $23 \%$ of the total global 
burden of disease is attributable to disorders in people aged 60 years and older. The leading contributors to disease burden in older people are cardiovascular diseases $(30 \cdot 3 \%$ of the total burden in people aged 60 years and older), malignant neoplasms $(15 \cdot 1 \%)$, chronic respiratory diseases $(9 \cdot 5 \%)$, musculoskeletal diseases $(7 \cdot 5 \%)$, and neurological and mental disorders $(6 \cdot 6 \%)$ (Note 3$)$. While rates of severe disability have declined in high-income countries over the past 30 years, there has been no significant change in mild to moderate disability over the same period. Common conditions in older age include hearing loss, cataracts and refractive errors, back and neck pain and osteoarthritis, chronic obstructive pulmonary disease, diabetes, depression, and dementia.

The present finding reveals that about 67.3 percent of the women reported having some chronic disease, such as arthritis and joint pain by 28.0 percent, followed by 20.7 percent reported blood pressure disorders and another 19.8 percent suffered from diabetes. 8.1 percent women under study reported asthma, respiratory diseases and thyroid disorder. As far as seeking treatment of these health problems is concerned, 38 percent women did not take any treatment for their illness due to poor economic condition, neglect on the part of the family members and distance of available health facilities. Around more than one-fourth deprive themselves of regular health check up while 32.7 percent women went for check up when it was serious.

It is interesting to mention that about 52.0 percent women were accompanied by no one during their visits for health check up which they found to be unsafe in this age. With regard to balanced diet and health supplement is concerned (TO BE DELETED), the study reveals that for 28 percent of women balanced diet was a distant dream as they stated, "getting three meals a day is hardly done what to talk about balanced diet", 39.5 percent women said that they did take sometimes followed by 35.5 percent who took balanced diet on regular basis. Needless to say that these women belonged to either upper middle classes or upper income groups. With regard to health supplement, almost 45.0 percent women did not take any health supplements such as vitamins and tonics, 35 percent did take various health supplements, 20 percent stated taking it sometimes.

\subsection{Respondents'Perception of Fitness (Physical and Mental)}

Regular physical activity (PA) and proper nutrition are the two major determinants of a healthy life style. Taken individually and collectively, they can help reduce obesity-related risk of chronic disease, and improve indicators related to chronic disease (e.g., blood lipid and glucose levels) (Note 4). Keeping in mind this view in mind, respondents were asked to respond about their physical activities and their perception about physical fitness. In terms of their perception of own physical fitness, 18.8 percent women considered themselves extremely unfit and 32.7 percent women perceived themselves as moderately fit. This is corroborated from the fact that only 8.0 percent women practiced yoga and meditation. Though walking is practiced by 30.3 percent only 15.2 percent performed some light free hand exercise to keep fit and active.

Women were also asked to mention the motivating factors for physical fitness and the barriers of it. It was found that 29 percent women mostly from upper or upper middle class 
who did exercise stated that there were primary three motivational factors; health/medical reasons, reduce stress and weight, most important, time to spend with friends. With regards to the barriers of physical activities, the majority of the respondents 59 percent stated time constraint, familial responsibilities and obligations, exercise is a hassle, lack of support from family members and social inhibitions. Thus, the preferred motivation of physical activities was weight loss, health concerns and time to spend with friends and the barriers to physical activities were lack of time, family responsibilities and obligations and social inhibitions.

\subsection{Feelings of Depression, Loneliness and Neglect}

Depression or the occurrence of depressive symptom, loneliness and neglect is prominent amongst older people that affect their wellbeing and quality of life. Many studies have demonstrated that the prevalence of depressive symptoms increases with age (Kennedy, 1996). A study conducted by Chou and Chi (2001) revealed that elderly people living alone have a higher level of financial strain, more depressive symptoms than others and have a lower level of satisfaction with life. Similarly in the present study too, respondents have reported financial crisis, due to lack of the source of income. Similarly a study done by Nalini (2000) also reveals that "feeling of insecurity," "Loss of dignity" and "Lack of emotional support" becomes prominent if elderly women are neglected or ignored by the family. In my study it was found that 36 percent women reported to have suffered from depressive symptoms, loneliness and neglect on the part of family members. Statement like "Puri Zindagi hi ek afsos hain" (whole life is a regret); "ajaye bhagwan aur le ke jaye"(I wish I could die);Akelapan bhot darata hai (loneliness is very scary), Parivar wale apne masti mein rahte hain aur koyee puchta nahee hai; hamri bhi kuch khwhesein hain; hame bhi unka sath chaheye( members of the family are enjoying their life; no one is bothered about our feelings and needs; we also need their company) reflect their depression, loneliness and neglect, for which less than 11 percent women sought counseling/medical help. Few of the respondents' 7.3 percent and 4.8 percent women reported to consume tobacco and alcohol respectively to come out of their depression and anxiety.

\subsection{Sleep Pattern of the Respondents}

Over the past few decades the discussions about how sleep changes with age has grown significantly. It has been revealed by researchers that there are typical age-related, normal changes that occur in sleep patterns. More than one-half of the elderly have at least one sleep complaint (Foley DJ, et al., 1995). When people age their sleep patterns can begin to become more and more fragmented. This is because as we age, irregular sleep patterns and sleep disorders start to become much more common. Depression is twice as common in old age compared to young adults, and this can significantly affect the quality and the quantity of sleep. Hence, understanding sleep disorders in older adults is vital as it has deep impact of on quality of life, cognitive functioning, and health outcomes.

Keeping in mind this idea, I tried to explore whether the women under study felt any sleep disorder or change in sleep pattern. The research reveals that 40.0 percent women reported disturbed sleep pattern on a regular basis in everyday living followed by 34.7 percent reported sleep disturbance sometimes but they did not seek treatment and 25.3 percent women 
reported sound and effective sleep cycles. The reasons for disturb sleep cited by the women were more related to anxiety like taking care during illness, chronic diseases and medication, , changes in life style(retirement, change in daily structure), and psychosocial stressors like financial and emotional insecurity, fear of death etc. About 38 percent of the women stated that due to some changes in their life such as the death of a loved one, moving from a family of her own to son's home (retirement or death of spouse which is traditionally accepted norm in Indian society), or physical limitations due to illness, had caused sleep difficulties. Hence, our data clearly indicates that all three factors i.e. psychological well being, psychological distress or health factors impacted the sleep pattern of the women under study.

\subsection{Respondents's Views on Me-Time or Leisure Time Activities}

Participation in leisure activities has been associated with a number of positive cognitive, physical, and emotional outcomes as we grow older. Havighurst (1973) stated that engaging in a leisure activity means taking a break from the stress of human relationships and restoring balance in one's life; in addition, it is an attempt to embrace new challenges and experiences as well as the pursuit of enjoyment. Therefore, the leisure activities of elderly women living alone are a crucial determinant of a successful life in old age (Rowe JW, Kahn RL (1997). So, if their leisure activities become insufficient or if their social activities are decreased, they eventually become self-centered which increases their depression and loneliness.

In the present study question regarding me-time or participation in leisure time activities generated vivid answers from these older women. For instance, 43 percent women women rarely take out time for themselves, 26.1 percent reported using their me-time always for activities such as rest and relaxation, visiting friends/neighbour and caring for grandchildren, time in kitchen related activities and 17.6 percent prominently on religious and spiritual quests followed 13.3 percent watching television or listening to music and reading. It was interesting to notice that those women who were using their time in various leisure time activities' were found more healthier, self reliant, and had positivity towards life than those who who (TO BE DELETED)were not using time for leisure activities. More or less same observation is made by Lee BJ, Hong SW. (2012) in their study on older peoples' leisure time activities when they say that participation of elderly women in leisure activities leads to the improvement of their physical and mental confidence, contributes to their psychological well being, and improves their health. It also drives them to pursue a pleasant life and self-worth, and enhances their self-reliance. However, factors like health status, psychological well-being, economic status, religion/caste, level of depression, family structure, and loneliness were found to affect the women's participation in leisure activities.

\subsection{Family Relationships and Decision Making}

Aging brings in a change in family dynamics. The quality of family relationships, including social support (e.g., providing love, advice, and care) and strain (e.g., arguments, being critical, making too many demands), can influence well being. Substantial evidence consistently shows that social relationships can profoundly influence wellbeing across the life course (Umberson $\&$ Montez, 2010.). Family connections can provide a greater sense of meaning and purpose as well as social and tangible resources that benefit well-being (Hartwell \& Benson, 2007; 
Kawachi \& Berkman, 2001). Social support may provide a resource for coping that dulls the detrimental impact of stressors on wellbeing (Thoits, 2010) and support may also promote well-being through increased self-esteem, which involves more positive views of oneself (Fukukawa et al., 2000). Those receiving support from their family members may feel a greater sense of self-worth, and this enhanced self-esteem may be a psychological resource, encouraging optimism, positive affect, and better mental health (Symister \& Friend, 2003). As women past 60 years they are in a position to command more authority in the household where their spouses are aging as well. In Indian society particularly children are expected to take care of their elderly parents.

It was observed that 95.3 percent of the elderly women living in the families had social support. On an average though more than 78.0 percent of the women mentioned that they were given due respect within their households and that they actively participated in the decision making but 21.0 percent of these women had negative self image and low confidence over themselves and felt that the attitude of younger generation towards them was not respectful. They also responded that people perceive them through negative lens such as unworthy, dependent, weak, unattractive and burden on the family. They also added that due to the modern life style in the metro cities and the nature of job have impacted the care system especially for the elderly.

\subsection{Issue of Elderly Abuse, Safety and Security: Private and Public Domain}

The potential for elderly abuse, or the neglect and/or physical and emotional abuse of dependent elderly persons, creates one very disturbing aspect of older adulthood. Neglect may take the form of withholding food or medications, not changing bed linens, or failing to provide proper hygienic conditions. Physical abuse may occur as striking, shoving, shaking, punching, or kicking the elderly. Emotional abuse may take the form of verbal threats, swearing, and insults. Estimates are that approximately 5 percent of American older adults receive abuse each year.

Out of the 200 women in 60 years and above age cohort about 18.8 percent women reported to have suffered from domestic violence in their life at the hands of husbands, son and daughter in-law such as striking, shoving, shaking, punching, or kicking. Emotional abuse like insulting them in front of friends, threatening them for sharing their woes with friends or neighbours, leaving them alone at home, locking them inside during parties, etc. was reported by 23 percent. More than half of the women who have faced abuse whether physical or emotional remained silent to the violence inflicted on them, while 11.7 percent have cried or ignore the abuse and carry on with their lives. It was reported by the respondents that often the fear of societal rebuke, patriarchal mindset and primarily financial dependency the women tolerated such acts of abuse and did not take any steps against it. Moreover, only 33.9 percent of women in this age-group were aware about their legal rights while the majority of them remained ignorant and thus vulnerable.

Looking at the issue of violence and abuse in the public domain, it is a matter of concern that 35.2 percent of the older women did not feel safe in the city and they had primarily cited fear of theft, dacoity and snatching i.e.17.0 percent as the rooting cause. About 15.2 percent and 
11.8 percent women respectively cited unsafe night time travel and associated transportation problem and crime against women and older as the cause for insecurity. Road rage and petty fights among the youngsters on the streets was cited by 10.1 percent older respondents and about 40.0 percent and 28.0 percent respondents respectively did not access public toilets and parks for safety reasons. Given the very low awareness about any of the public policies in India in the surveyed sample in general, and this age group in particular was even more ignorant 27.3 percent about the policy for the elderly population in the country.

Shamlata Sharma, a 65 year old respondent shared her experiences of safety and security in public domain and the trauma she was still having;

She was attacked by motorcycle bound snatchers in public on her way from buying milk in the evening in the residential area. She was pushed from behind and her gold chain was snatched from her neck. She lost her balance and fell on the road bruising her face and injuring her knees. The snatcher caught hold of her chain and dragged her with the motorcycle, further bruising her neck. She tried screaming but her voice got chocked due to the impact of the injury. The passer-by's helped her and rushed her to the nearest hospital.

She has been taking sleeping pills since then as her sleep is disturbed. Shamlata's knee still pains and there is a visible injury mark on her neck. Will she be compensated for the mental and physical trauma she faced for lack of state role in stopping crime is the question she asks.

These incidents not only expose their vulnerability but also lead to impeding trauma in their minds. They are hesitant to move out freely for fear of being attacked, certainly taking a toll on their wellbeing.

\subsection{Psycho-Social Wellbeing: Stressors and Coping Mechanisms}

For the analysis of well being of elderly women, in the present study five important components i.e. family bonding, inner happiness contentment, good health, Social acceptance, Autonomy and Independence and Security and Safety have been taken. Family bonding (41.9 percent) was reported as one of the major factor for the overall well being in the old age. The reason put forward by the respondent; a good, cordial and respectful family bonding is first and foremost factor for the well being of any individual in any age in general and in old age in particular that had direct impact on their well being, followed by 18.7 percent who considered inner happiness and contentment as important and that is an outcome of strong family bonding, followed by 15.7 percent women who stated social acceptance from their family and society in general, their autonomy and independence as one of the essential component of wellbeing, 11.7 health as important factor for the well being and security and safety stated by 7.5 percent women. 
Table 1. Components of Wellbeing: Respondents' View

\begin{tabular}{lc}
\hline \multicolumn{1}{c}{ Components of Wellbeing } & \% Women \\
\hline Family Bonding & 41.9 \\
Happiness \& Contentment & 18.7 \\
Social acceptance, Autonomy and Independence & 15.7 \\
Health & 11.7 \\
Security and Safety & 7.5 \\
Total & 100 \\
\hline
\end{tabular}

Source: Field Survey, 2018

\subsection{Sources of Happiness: Respondents' View}

It is interesting to note that 31.5 percent women value respect, appreciation and adulation from family members and immediate society such as friends and neighbours gives the highest degree of happiness (Table 2). This is what is presumed to be compromised in the later years of one's life, where changing age related roles and assigned household responsibilities lead to alienation from younger household members often engaging in bitter power struggles, isolation and neglect of the older women. Age related illnesses usually restrict mobility outside homes and thereby increases the dependency of the older women on their younger family members; children and grandchildren in order to perform simple activities in daily life. This is assumed to create disharmony and conflicts in family relationship criss-crossing the generations and it culminates into emotional abuse on the elderly. Freedom of expression and autonomy as second most important source of happiness was cited by 20.1 percent followed by 16.0 percent cited spending quality time with Family and children's Achievement. Similarly social interaction, support, social networking and financial Stability were found to be the another important source of happiness with 14.4 percent women in the group resonating the same. Often it is not unusual to observe that with age especially the women lose the sense of autonomy and authority within their households. Age related role transformations within the family reverses the dynamics of interaction, decision-making and negotiating pattern in traditional family set up. Thus often the aged women feel isolated and alienated within their house and neighbourhood where they and their opinions are made to feel less valuable and are given no heed to or totally suppressed. Freedom of expression ranks fourth in the list of happiness and 13.4 percent of such women agreed to the same. Religion and spirituality is slightly more important than their counterparts.

Signs of ageing are witnessed through bodily changes more than through the cognitive degeneration or social neglect. Body and physical appearance holds importance in views with women perceiving themselves positively for their bodily attributes. With positivity also comes critical evaluation of self. 


\section{Macrothink}

Table 2. Sources of Happiness: Respondents' View

\begin{tabular}{lc}
\hline \multicolumn{1}{c}{ Sources of Happiness } & \% Women \\
\hline Respect \& Appreciation & 31.5 \\
Freedom of Expression and Autonomy & 20.1 \\
Quality time with Family \& Children's Achievement & 16.0 \\
Social Interaction, Financial Stability & 14.4 \\
Leisure/Hobbies/travel/Food & 10.0 \\
Religion/Spirituality & 8.0 \\
Total & 100 \\
\hline
\end{tabular}

Source: Field Survey, 2018

\subsection{Stressors and Coping Mechanism}

It is generally said that old age and stress go hand in hand. Stress may be defined as an unpleasant state of emotional and physiological arousal that people experience in situation that they perceive as dangerous or threatening to their wellbeing. It can also be defined as event or situation that causes tension, pressure, or negative emotions such as anxiety and anger and also as the response to these situations. This response can be seen in term of physiological changessuch as increased heart rate and muscle tension-as well as emotional and behaviour changes. However, most psychologists regard stress as a process of common experience. The physical or psychological demands from the environment that cause this condition are called stressors.

Almost $4 / 5^{\text {th }}$ of the women have claimed to experience stress and anxiety from daily life. Stressful family relationships and lack of family care precipitates the elderly's poor psychological well- being (Litwin and Shiovitz 2006). Twenty -seven percent respondents stated that they felt neglected in the family but the respondents kept themselves busy by taking up various household activities like looking after their grandchildren, doing small household chores etc. and only 13.3 percent of them reported that they were humiliated by their daughters-in-law and also their sons did not care for them. Women have responded that it is monetary problems and financial crisis (20.0 percent) that triggers stress along with work burden (15.8 percent) and family disharmony (15.7 percent) (Figure 1). 


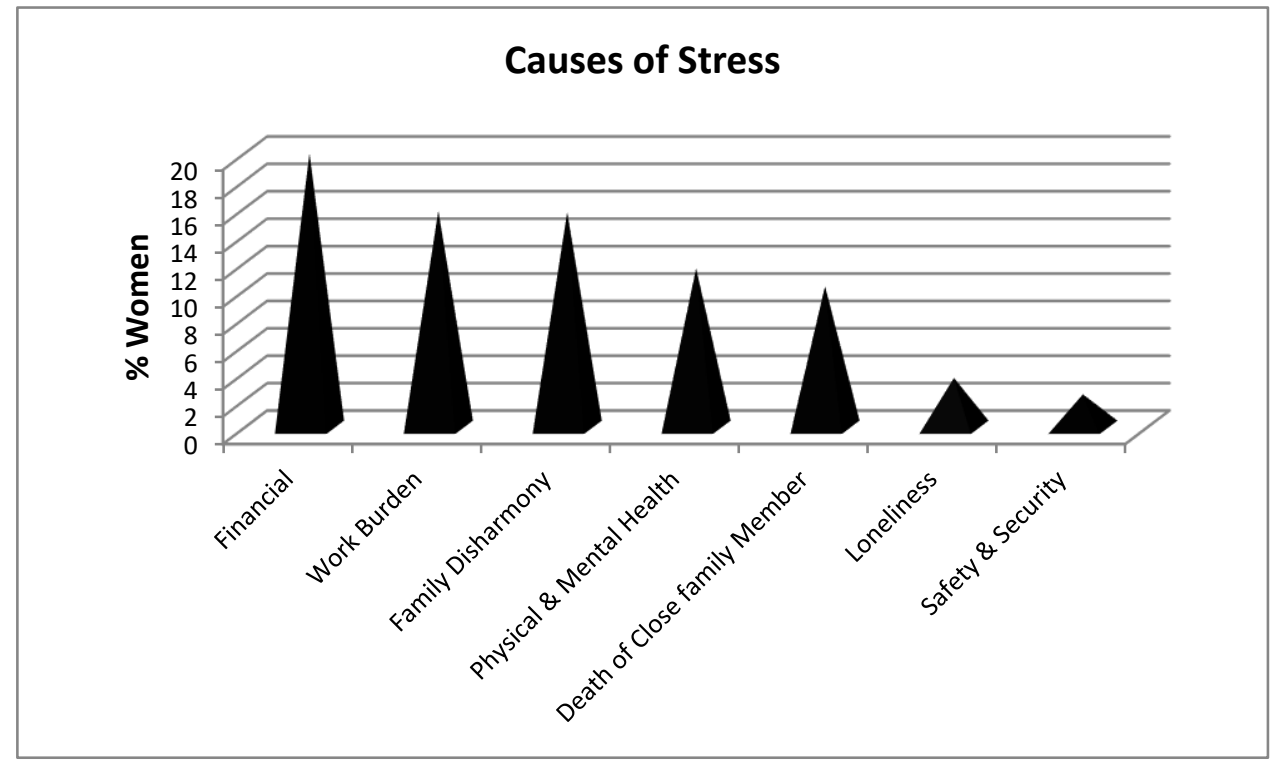

Figure 1. Causes of Stress among Women

Source: Field Survey, 2018

The health concerns of self and of family members do also affect the women. Loneliness and isolation is another determinant that has come up as a stressor for women in this age-group.

\subsection{Coping Strategies Used by the Women}

Generally, coping strategies is defined as recognized constituents of the construct psychological resilience, that are mirrored in instruments which assess behaviors by which people alter the environment and regulate their cognitions and emotions when challenged by stressful events of different natures. Usually, these tools are based on the categorization of coping strategies into those oriented to problem solving (e.g. making an action plan) and to managing emotions (e.g. expressing an emotion), and those oriented to positive actions (e.g. accepting the problem) and negative actions (e.g., expressing hostility). Further, Characterizing coping strategies from the perspective of adaptation and development makes important contributions, particularly pertaining to the description of strategies that are beneficial to controlling and preventing anxiety and depression, adapting to chronic illness and to widowhood, and maintaining quality of life among the elderly. 
Table 3. Coping Strategies Used by the Women

\begin{tabular}{lc}
\hline \multicolumn{1}{c}{ Coping Strategies } & \% Women \\
\hline Participation in Religious/Spiritual Activities & 28.3 \\
Social interaction(friends, neighbours and relatives) & 24.9 \\
Leisure time activities & 17.0 \\
Crying & 12.3 \\
Walking, Yoga/meditation \& other Physical Activities & 10.2 \\
nostalgia/sharing memories & 7.3 \\
Total & 100 \\
\hline
\end{tabular}

Source: Field Survey, 2018

There is a common belief particularly in Indian subcontinent that in old age people tend to become more and more spiritual for various reasons. Spirituality can help to develop healthy behaviors and lifestyles; find psychosocial support; and effectively deal with suffering, life's problems, and negative emotions such as stress, anxiety, fears, anger, and frustration (Hadzic, 2011). Numerous empirical findings indicate an effect of spirituality/religion on physical and mental health. Spirituality and religion have positive associations with wellbeing, general psychological function, and marital satisfaction.

In the present study it was observed that the spirituality and community participation through spiritual or religious activity (28.3 percent) ranked as one of the primary coping strategies of the elderly women to handle stress, loneliness and anxiety. Many women turned to satsang or Ijtima (a religious gathering) and group religious activities to have peace and to release stresses. More precisely, the respondents expressed that their involvement in the religious activities is a kind of anxiety buster. So the elderly women under study with good spiritual outcome experience low level of stress compared to elders with low level of spiritual belief. Women also pointed out that the spiritual inner resources give a feeling of strength to them in time of crisis, when dealing with uncertainties of life. Shigaraki (1983) opines that whether or not people attain enlightenment, religion is considered to provide a peace of mind by integrating and harmonizing various contradictions, confrontations, and confusions in a daily life by providing existential meaning and reality and the principle of life. To an extent, religion/spirituality provides a sort of social support in the form of personal contact with other people at religious gatherings with whom they could share their thoughts along with self satisfaction. It is important to mention that this coping was irrespective of caste, communities and economic status of the respondents.

Social interaction including friends/relatives and neighbour was found to be second most cited coping mechanism by the women under study. In the present study also social interaction especially with friends and relatives was found to be the second most cited (24.9 percent) coping strategies by the women. They further added that whenever there was a feeling of depression and loneliness, they either talked or visit their friends, neighbours or relatives. Here again it ws found that this mechanism was irrespective of caste/class and communities. 
Montross et al. (2006) in their study have pointed out that there is a positive relationship between friendship and successful ageing. It suggests that larger the number of close relatives and the more frequent is the contact with friends, the higher is the score of successful ageing indicators among elders. While 17 percent women stated to keep themselves busy in leisure time activities as coping mechanism through various activities like watching television, listening to music, cooking, kitty party, yoga club and so on but it was found more among the affluent class women or middle class women than economically weaker sections of the society.

However, it is worrisome to note that 12.3 percent of the women under study stated crying as a mechanism to overcome their loneliness, depression and anxiety rather than consulting a counselor or sharing it with friends. When asked the reason, majority of them stated lack of family support and economic resources mainly among the lower class or lower middle class women. Further, 10.2 percent were resorting to Yoga and other physical activities, meditation to keep themselves relaxed, tension free and refreshed, while 7.3percent stated remembering the old happy memories and sharing these with their grandchildren and friends gives nostalgia about feeling of achievement. More precisely, it was found in the present study that those most satisfied with life used more development strategies and, less frequently, non-adaptive strategies than those with an intermediate level of satisfaction. It was also found that indicators of well-being, including happiness, positive affects and satisfaction with life, were found to be related to low morbidity, fewer depressive symptoms and less pain.

\subsection{Aspirations, Dreams and Regrets: Women's response}

Overall satisfaction quotient of the elderly from life is good barring the 16.3 percent women who claimed to be dissatisfied. This is understood from the 46.6 percent women respondents in this age group who have responded as having regrets in their life; the principal being the inadequate and incomplete education and early marriage. About 23.3 percent women repented that low level of education has compromised their employability and earning capacity and have made them financially dependent. Anisha khan, 62 years of age have regret that, 'I wanted to go to school, to study but circumstances were not favourable'.

Another 26 percent women have mentioned about low economic background, not owning house and assets and not making good career choices when young as source of their regrets. Many repent to have given up their careers and jobs owing to early marriage and motherhood. Death of spouse, ill-health of children has been reported by 15.5 percent women. Thus about 22.4 percent regret that older women have reported stems from societal patriarchal, judgmental and stereotypical behaviour more in terms of perceiving them as burden and not worth

It was disheartening to see 43.0 percent women to state that none of their dreams have been fulfilled in the lifetime. Although more than 50.0 percent of the respondents did not share their aspirations, for another 10.3 percent dreams have no place in their lives owing to their old age and their self-sacrificing family role. 'Hum budhe, garib, vidhwa auraton ka koi sapna hota hai kya?' (Do the old, poor widow women have any dream?)they ask pensively. Though 23.1 percent view their future to be secured and comfortable, 9.2 percent women view their future to be active, fit and healthy and 15.7 percent did aspire to perform their 
roles of a 'good mother, grandmother and wife'. About 10.1 percent wanted their children's future life to be well established alongside desiring to lead a 'happy, respectful life with integrity'. Life satisfaction continues to be an important construct in the psychosocial study of aging. But more than 10.0 percent of the women stated that they had no hope for their future as their statements like 'want to die and are waiting for death' and that 'we don't see future' 'hardly anybody bother for us' clearly reflects their loneliness, stressful family relationships and lack of family care resulting into lower level of satisfaction with life.

\section{Conclusion}

The age group is considered as the transcending age where, in the words of the respondents they were aged, elder, senior citizen or not so young and attractive. For some however this age was an age to reinvent themselves and their social roles, along with retirement in case of working women. Increase in health related problems and mobility issues along with depression were seen more in this particular age segment. Dependence on other family members for emotional, financial and social needs were also seen increased in respondents and came out as major cause of depression and anxiety. Family bonding and social acceptance were the major source of happiness for the women under study. Safety security and elderly abuse were the major concerns of the women under study which need attention from all concerned especially the state and civil society. Those who were at the lowest income and literacy level were further marginalized and needed help from state.

Role of state in terms of ensuring timely old age and widow's pensions was desired by them. Not being able to benefit from and access to these schemes led to frustration which had an adverse affect on their well-being. They were seen more drawn to religion which was a source of community participation to overcome various factors affecting their well being. To safe guard these women's well-being from further deterioration, there arise a need to strengthen the deliverables in each government schemes.

It is important that the state, civil society and community recognizes the rights and needs of the elderly women and make suitable polices legislations and effective implementation of health and security schemes that already exist. Specific state interventions are required for the aged women, they being most vulnerable and for the aged who are below the poverty line. There is a need to protect the human rights of the elderly and have gender just laws and policies to ensure adequate economic and social protection during old age. Thus, to conclude problems of the elderly vary from society to society and have many dimensions especially in our country where aging is gendered. However, the disintegration of the joint family system and the impact of economic change have brought significant changes and in the traditional value system and hence, the duty and obligation of the younger generation towards the older generation is being skewed. At the same time due to these socio-economic changes the elderly especially the women are caught between the decline in traditional values on one hand and the absence of an adequate social security system by the state on the other hand thus, finding it difficult to adjust in the family in their later age. 


\section{Acknowledgment}

This paper and the research behind it would not have been possible without the support of my research team. Expertise of one and all have improved this study in innumerable ways and saved me from many errors. However those that inevitably remain are entirely my own responsibility. My thanks are due to all the respondents who participated whole-heartedly in carrying out this research. Last but not the least, I owe special thanks to my daughter Sanaa in preparing the figures and graphs and my husband Prof. Ejaz for his constant support in completing this paper.

\section{References}

Asharaf, A. (2005). Legal protection for women in old age. Social Welfare, 52, 7-9.

Bergeron, L. R. (2001). An elderly abuse case study: Case gives stress or domestic violence. Journal of Gerontogical Social Work, 34(3), 47-63. https://doi.org/10.1300/J083v34n04_05

Bhat, K. (2001). Ageing in India: Drifting international relations, challenges and option. Cambridge Journal Online, 21, 621-640. https://doi.org/10.1017/S0144686X0100842X

Bhatia, S. P., Swami, H. M., Thakur, J. S., \& Bhatia, V. (2007). A study of health problems and loneliness among the elderly in Chandigarh. Indian J Community Med, 32, 255-8.

Borrell, C., Regidor, E., Arias, L. C., Navarro, P., Puigpinós, R., Domínguez, V., et al. (2011). Inequalities in mortatity according to educational level in two large Southern European cities. Int. J. Epidemiol, 28, 58-63. https://doi.org/10.1093/ije/28.1.58

Chou, K., \& Chi, L. (2000). Comparison between elderly persons living alone and those living with other. Journal of Gerontology Social Work, 33, 51-56. https://doi.org/10.1300/J083v33n04_05

Dandekar, K. (1993). The Elderly in India New Delhi: Sage publishers.

Foley, D. J., Monjan, A. A, Brown, S. L., Simonsick, E. M., Wallace, R. B., \& Blazer, D. G. (1995). Sleep complaints among elderly persons: an epidemiologic study of three communities. Sleep, 18, 425-32. https://doi.org/10.1093/sleep/18.6.425

Foottit, J., Anderson, D. (2012). Association between perception of wellness and health-related quality of life, co-morbidities, modifiable lifestyle factors and demographics in older Australians. Australia's J Ageing, 2012(31), 22-27. https://doi.org/10.1111/j.1741-6612.2011.00526.x

Fukukawa, Y., Tsuboi, S., Niino, N., Ando, F., Kosugi, S., \& Shimokata, H. (2000). Effects of social support and self-esteem on depressive symptoms in Japanese middle-aged and elderly people. Journal of Epidemiology, 10, 63-69. https://doi.org/10.2188/jea.10.1sup_63 
Graham, J. R., \& Shier, M. L. (2010). The social work profession and subjective well-being: The impact of a profession on overall subjective well-being. British Journal of Social Work, 40(5), 1553-1572. https://doi.org/10.1093/bjsw/bcp049

Hartwell, S. W., \& Benson, P. R. (2007). Social integration: A conceptual overview and two case studies. In W. R. Avison, J. D. McLeod, \& B. Pescosolido (Eds.), Mental health, social mirror (pp. 329-353). New York: Springer. https://doi.org/10.1007/978-0-387-36320-2_14

Havighurst, R. J. (1973). The leisure activities of the middle aged. Am J Social 1973, 63(2), 152-162. https://doi.org/10.1086/222172

KaKawachi, I., \& Berkman, L. F. (2001). Social ties and mental health. Journal of Urban Health-Bulletin of the New York Academy of Medicine, 78, 458-467. https://doi.org/10.1093/jurban/78.3.458

Kennedy, G. J. (1996). The epidemiology of late-life depression. In Kennedy, G. J. (Ed.), Suicide and depression in late life: Critical issues in treatment, research and public policy. New York, John Wiley and Sons, 1996, 23-37.

Kunzmann, U., Little, T. D., \& Smith, J. (2000). Is age-related stability of subjective well-being a paradox? Cross-sectional and longitudinal evidence from the Berlin aging study. Psychology and Aging, 15(3), 511-526. https://doi.org/10.1037/0882-7974.15.3.511

Lee, B. J., \& Hong, S. W. (2012). The effect of older people's leisure activities on their self-esteem and life satisfaction. Northeast Asia Tour Res 2012, 8(2), 139-156.

Lena, A., Ashok, K., Padma, M., Kamath, V., \& Kamath, A. (2009). Health and social problems of the elderly: A cross sectional study in Udupi taluk. Karnatka Indian $J$ Community Med, 2009(34), 131-134. https://doi.org/10.4103/0970-0218.51236

Litwin, H., \& Shiovitz, E. (2006.) Association between activity and well- being in later life: What really matters? Ageing and society, 26, 255-242. https://doi.org/10.1017/S0144686X05004538

Mcnulty, J. K., \& Fincham, F. D. (2012). Beyond positive psychology? Toward a contextual view of psychological processes and well-being. American Psychologist, 67(2), 101-110. https://doi.org/10.1037/a0024572

Montross, L., Depp, C., Daly, J., Golshan, S., \& Moore, D. (2006). Correlates of self-rated successful ageing among community dwelling other adults. The American Journal of Geriatric Psychiatry, 14(1), 43-51. https://doi.org/10.1097/01.JGP.0000192489.43179.31

Nalini, B. (2000). Institutional care for the aged: Life twilight years. Indian Journal of Community Guidance Service, 6(1), 27-29.

Ortiz Arriagada, J. B., \& Salas, M. C. (2009). The psychological well-being of the elderly and their relation with self-esteem and self- efficiency: nursing contribution. Ciencia 
Enfermeria, $X V, 25-31$.

Penhale, B., \& Kingston, P. (1995). Social perspectives on elder abuse. Family violence and caring professions. Basingstoke: Macmillan. https://doi.org/10.1007/978-1-349-13306-2

Prakash, I. J. (2001). Elder abuse: Global response and Indian initiatives. Indian journal of social Work, 62, 446-463.

Prieto-Flores, M. E., Mayoralas, G. F., Pérez, F. R., Bosque, R. L., Rodríguez, V. R., Mohamed, K. A., et al. (2008). Socio-demographic and health factors explaining emotional wellbeing as a quality of life domain of older people in Madrid Spain. Rev. Esp. Salud. Pública, 82, 301-313. https://doi.org/10.1590/S1135-57272008000300006

Rowe, J. W., \& Kahn, R. L. (1997). Successful aging. Gerontologist 1997, 37(4), 433-440. https://doi.org/10.1093/geront/37.4.433

Spirduso, W. W., Francis, K. L., \& Macrae, P. G. (2005). Physical Dimensions of Aging, Human Kinetics, Champaign, IL, USA.

Steverink, N., Westerhof, G. J., Bode, C., \& Dittmann-Kohli, F. (2001). The personal experience of aging, individual resources, and subjective well-being. J. Gerontol. B Psychol. Sci. Soc. Sci, 56B, 364-373. https://doi.org/10.1093/geronb/56.6.P364

Symister, P., \& Friend, R. (2003). The influence of social support and problematic support on optimism and depression in chronic illness: A prospective study evaluating self-esteem as a mediator. Health Psychology, 22, 123-129. https://doi.org/10.1037/0278-6133.22.2.123

Thakur, R. P., \& Nikumb, V. B. (2013). 'Health Problems Among the Elderly: A Cross-Sectional Study' Ann Med Health Sci Res. 2013 Jan-March, 3(1), 19-25. https://doi.org/10.4103/2141-9248.109466

Thoits, P. A. (2010). Stress and health: Major findings and policy implications. Journal of Health and Social Behavior, 51, S41-S53. https://doi.org/10.1177/0022146510383499

Umberson, D., \& Montez, J. K. (2010). Social relationships and health: A flashpoint for health policy. Journal of Health and Social Behavior, 51, S54-S66. https://doi.org/10.1177/0022146510383501

World Health Organization Collaborative Programme supported by the Government of India. Multi-centric study to establish epidemiological data on health problems in elderly. Retrieved from http://www.whoindia.org/LinkFiles/Health_Care_for_the_Elderly_Multicentric_study_h ealthcareelderly_exe.pdf 


\section{Notes}

Note 1. According to Population Census 2011 there are nearly 104 million elderly persons (aged 60 years or above) in India; 53 million females and 51 million males. A report released by the United Nations Population Fund and Help Age India suggests that the number of elderly persons is expected to grow to 173 million by 2026 .

Note 2. "The State shall within the limits of its economic capacity and development, make effective provision for securing the right to work, to education and to public assistance in cases of unemployment, old age, sickness and disablement, and in other cases of undeserved want."

Note 3. Martin et al 2015 'The burden of disease in older people and its implications for health policy and preacticeAging' Volume 385 Issue 9967, P 549-562 February 2015.

Note 4. U.S. Department of Health and Human Services, author. Physical Activity and Health: A report of the Surgeon General. Atlanta: GCfDCaP, National Center for Chronic Disease Prevention and Health Promotion; 1996.

\section{Copyright Disclaimer}

Copyright for this article is retained by the author(s), with first publication rights granted to the journal.

This is an open-access article distributed under the terms and conditions of the Creative Commons Attribution license (http://creativecommons.org/licenses/by/3.0/). 